\title{
Los valores en las películas infantiles
}

\author{
Caso. Primaria Profesor Teodomiro Manzano
}

Verónica Ortega Ortiz

Daniel Alejandro Ramírez y Ramírez

Monserrat Ortiz Sánchez

Asesor

Esther Fragoso Fernández

\section{Introducción}

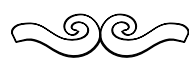

El objetivo de este estudio es identificar qué valores promueven las películas infantiles, es decir, enfatizar la influencia de los medios de comunicación en la conformación de los valores y actitudes de nuestros niños y niñas. Existe una llamada de socorro de la mayoría de los educadores ante la impotencia de sus acciones educativas frente a la potencia conformadora de los medios de comunicación concretamente de la televisión.

La sociedad actual está viviendo una de las más complejas situaciones que se han dado en el curso de la historia. El hombre necesita imperiosamente unos instrumentos que le ayuden a interpretarla. Hoy en día, el principal marco de referencia son los medios de comunicación social. La prensa, la radio, la televisión, el cine y la publicidad se configuran como narradores de la actualidad y aparecen como formas de explicación imprescindibles para conocer y comprender lo que está sucediendo dentro y fuera del entorno cultural.

El estudio de los medios de comunicación en la sociedad contemporánea se convierte así en una necesidad para los educadores. Se plantea la urgencia de realizar un estudio crítico y una formación específica en este sentido.

Asimismo, creemos indispensable, por las razones que más tarde se expondrán, el tratamiento exclusivo del medio televisivo desde el ámbito de la educación en valores. Por lo tanto, expondremos las visiones que se han aportado en este ámbito, culminándolas con la propuesta de una serie de acciones que, suponemos, tendrán un efecto positivo en nuestra infancia. No hay que establecer una lucha encarnizada contra la televisión y los Medios de comunicación social (MCS); estamos obligados a establecer una amistad con ellos, porque se trata de un elemento presente en nuestras vidas, querámoslo o no.

Por primera vez, en la era de los medios de comunicación, los niños son confrontados masivamente y a diario, trascendiendo los límites de clases sociales, regiones y naciones, con símbolos, opiniones y estilos de vida, que superan ampliamente lo que pueden transmitirles padres, educadores y maestros (Hensegst, 1981)

\section{Justificación}

La investigación se centra en la importancia de que el cine ha formado parte de la vida y formación ontológica de los niños por lo que se decidió investigar la forma en que los infantes perciben los valores universales a través de las películas infantiles.

Debido a que el cine es un medio que puede regularse de mejor manera que la televisión, la industria del celuloide ofrece la posibilidad de que los padres de familia conozcan y decidan lo que sus hijos consumen.

Una vez delimitando el concepto que las películas infantiles son aquellas proyecciones fílmicas dirigidas a un público infantil, se procedió, por medio de encuestas, a delimitar el tipo de men- 
sajes en valores que brindan ciertas películas de Walt Disney Pictures a los niños que las han visto, tomando como caso especifico La Sirenita, La Espada en la Piedra y El Rey León.

\section{Preguntas de investigación}

¿Se puede considerar que las películas infantiles son un producto que los niños consumen de manera frecuente?

¿Cuándo un niño consume los mensajes de las películas infantiles es guiado por alguien para entenderlos?

¿Qué valores identifican los niños en las películas infantiles?

¿El sexo del niño determina su preferencia por algún personaje de la película?

¿En estas películas se cumple la función de entretener y educar?

¿Los niños tienen la capacidad de identificar la diferencia entre bondad y maldad?

¿Qué tanto influye el cine en los niños para generar valores?

\section{Marco Teórico}

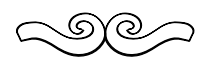

Nos basaremos en la noción de la niñez como un estado de bondad y que los impulsos naturales de los niños se deben aceptar como son. Esta teoría fue postulada por Jacques Rousseau en 1792 (Newman Phillip 2004, pp. 22-23); según él la naturaleza del niño es básicamente buena. Según el mismo Rousseau cuando los niños se enfrentan a valores contrapuestos o a presiones sociales, debían aprender a apoyarse y confiar en su capacidad para razonar.

De acuerdo con el Portal Infoamérica en su sitio web oficial hace referencia a Bandura y su pensamiento:

"Los medios de comunicación no sólo son susceptibles de ser observados, sino que actúan sobre los procesos psicológicos de la persona en la medida que crean imágenes, representaciones, modelaciones de la realidad, por lo que, consecuentemente, producen o modifican las conductas y el mecanismo cognitivo que precede a las conductas. A través de los medios, ésto es, mediante el cambio del medio ambiente social, se pueden variar los comportamientos. Además, los medios, especialmente los audiovisuales, cada vez más determinantes en la percepción de lo exterior, reproducen en sus prácticas narrativas los elementos básicos que desencadenan la actividad de la observación. Al tiempo, son capaces de fijar ciertas marcas o referencias que instruyen los mecanismos de autocontrol del individuo en sus comportamientos".

Piaget (citado por Labinowicz, 1986) menciona que: "El pensamiento es una actividad privada que puede incluir la creación de imágenes mentales; en el ensayo silente o repetición de sucesos pasados o futuros, o en la agradable asociación de experiencias vividas que pueden no haber ocurrido al mismo tiempo en la realidad".

La fantasía es una forma de pensamiento simbólico que se puede expresar verbalmente, en imágenes sensoriales o en acciones. El contenido de este pensamiento no se limita a la esfera de la realidad, pero se puede dirigir a la realidad, la fantasía es el procedimiento consiente de la actividad mental interna que tiene su origen en eventos del medio interno y externo (Klinger 1971).

En los estudios del psicólogo Kohlberg (1985, p.) se expone tres fases en el desarrollo del razonamiento moral:

-Fase premoral, se refiere a la relación con las necesidades e intereses propias.

-Fase convencional, se toma en cuenta la opinión de los demás y no se cuestiona la autoridad establecida.

-Principios morales, se respeta el bienestar de las demás personas y se actúa de acuerdo a principios éticos.

\section{Marco histórico}

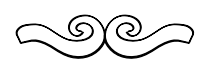

Orígenes del entretenimiento infantil

En una reciente publicación llamada (El mundo del Cine. Los grandes mitos del séptimo arte, Pp. 15, 67,145-146, 154) se encuentra que los niños se asomaban al mundo de los adultos a través de los cuentos, narraciones y leyendas que a lo largo de muchas generaciones se transmitían oralmente. Entre las obras infantiles más famosas en la historia se encuentran las recopilaciones de cuentos de los hermanos Grimm 


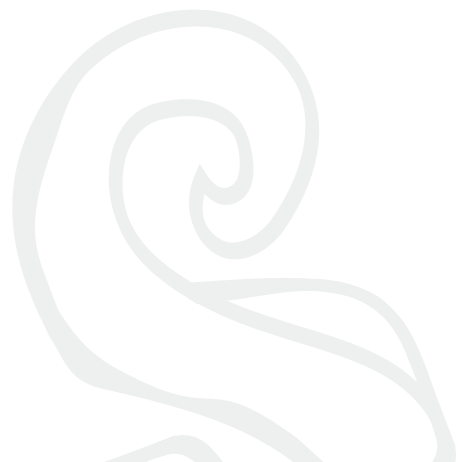

llamadas "Cuentos para la infancia y el hogar" dos volúmenes publicados en 1812 y 1815 . La colección fue ampliada en 1857 y se conoce popularmente como "Cuentos de hadas de los hermanos Grimm". Su extraordinaria difusión ha contribuido decisivamente a divulgar cuentos como "Blanca Nieves", "La Cenicienta", "Hänsel y Gretel" o "Juan sin miedo". Al parecer se llevaron al cine muchas adaptaciones infantiles de ellos y en la década de 1930 Walt Disney realizó su primero largometraje con dibujos animados. En 1937 Disney ganó el Oscar con "Blanca Nieves y los Siete Enanos.

\section{Marco conceptual @e}

Valores son considerados como las apreciaciones de un objeto, acto o pensamiento. Son la forma de expresión de la personalidad y están relacionados con nuestras tendencias y deseos. Actúan como estímulos provocando reacciones afectivas que determinan la conducta. La cultura se constituye por los distintos valores producidos por el espíritu humano. (Pliego, 2002)

Hermman Cohen (Fingermann, 1970, p. 47) indica que "el hombre actúa según ciertos valores que se dividen en individuales y sociales. Los valores individuales son los que efectúa el hombre para si mismo, algunos de éstos son la templanza, la resignación, la modestia, la felicidad y la justicia. Los que son considerados como valores sociales, son los que toman sentido para la persona como parte de una comunidad, considerados en este tipo es la justicia, la lealtad, la sinceridad y la honradez. Una conducta moral correcta se refiere al cumplimiento de los valores".

De acuerdo con el Ministerio de Cultura de España, en su sitio web oficial de Gobierno de España define película como: "toda obra audiovisual, fijada en cualquier medio o soporte, en cuya elaboración quede definida la labor de creación, producción, montaje y posproducción y que esté destinada, en primer término, a su explotación comercial en salas de cine".

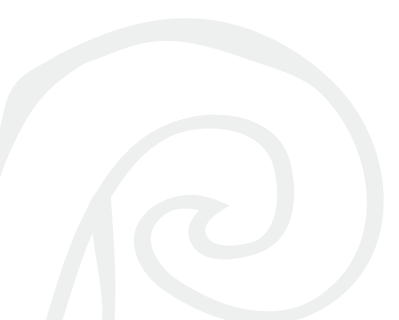

En el "Certamen Internacional de Cine-TV infantil (2004) citado en Soto, María El nacimiento y desarrollo del cine infantil en España y el Certamen Internacional de Cine para niños de Gijón se concluyó que Cine infantil es aquel "cuyo argumento, desarrollo y lenguaje audiovisual se adaptan, precisamente a la inteligencia y sensibilidad de los niños".

\section{Marco referencial $\curvearrowleft$}

El Cine Infantil como Instrumento Didáctico

En nuestra sociedad, aquellos valores en general que forman parte de la esencia del ser humano, que mejoran su calidad como personas y regulan su relación con los demás, se encuentran en desuso y decadencia. Nuestro desafío como educadores es la formación de los mismos desde la infancia con la ayuda innegable que nos brindan los medios audiovisuales, ya que los niños aprenderán valores y contravalores necesarios para desarrollarse como personas intelectualmente reflexivas. Hemos elegido para este fin la película infantil titulada: "Buscando a Nemo".

\section{Fundamentación}

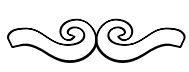

Los alumnos y alumnas ya tienen de por si un elevado conocimiento "intuitivo "de los medios y requieren una dinámica didáctica adecuada, que se basa en la motivación que los medios generan y los valores que estos transmiten, desde una perspectiva de interculturalidad, pensamiento crítico, actitud investigadora, descubrimiento y creación de sus propios mensajes como respuesta al medio." (De la Torre, 1998).

Esta cita nos manifiesta en forma inequívoca que los niños ingresan a la escuela con conocimientos previos de la pantalla chica y grande con lo cual nosotros debemos, a través de la película elegida:" Buscando a Nemo", alcanzar los objetivos previstos haciendo hincapié, no solo en la responsabilidad, la cooperación y la solidaridad (valores básicos en la película), sino también la posibilidad de poder disfrutar, reír o llorar y emocionarse con las acciones de los personajes con los cuales se sientan iden- 
tificados. Utilizar al cine como un instrumento didáctico abrirá las puertas para acercar al niño a los diferentes textos de las diversas áreas del conocimiento. De esta manera podremos abarcar los libros que vayan desde los cuentos, mitos, fábulas y leyendas hasta los de medio ambiente, ecología, enciclopedias, etc.

No debemos olvidar que la comunicación en el cine se produce en tres niveles sobre los cuales debemos trabajar:

Nivel 1: Sistema perceptivo, abarca vista y oído de estos sentidos depende el riesgo inmediato de la información.

Nivel 2: Sistema preceptivo secundario abarca imagen, sonidos (fonéticos y musicales), ruidos y señales, produciendo un reconocimiento y decodificación de lo observado.

Nivel 3: El mensaje que ingresa de forma subconsciente.

\section{Los medios de comunicación social}

Hoy en día, los MCS se han convertido en uno de los agentes educativos, junto con la familia, la escuela y los demás ámbitos de la vida de la persona, que contribuyen a configurar su forma de pensar y actuar. Su impacto en las sociedades humanas ha sido considerable (McLuhan, 1982.)

McLuhan vio a los medios como transformadores del ser humano. En una sociedad de la comunicación en la que vivimos, caracterizada por la intensificación del intercambio de comunicaciones, las nuevas tecnologías han decantado ya la comunicación hacia lo que algunos denominan el «imperio de la imagen » (Casas, 1996, p. 133). La imagen hace que los nuevos medios estén dirigidos hacia el presente y no hacia el pasado, como lo está la imprenta.

Para diversos autores, los MCS aparecen como mediadores de cambios sociales y culturales, a partir de su influencia sobre las imágenes y las representaciones sociales, y en particular sobre las representaciones de cambio social.
Además, los medios se anclan en lo que es noticia, lo que es novedad, lo que choca con lo habitual y con la norma establecida, es decir, en temas (objetos informativos) relacionados con transformaciones del entorno social, quizá con el cambio social. Para ello, utilizan dos tipos de mediaciones (Serrano, 1986):

a) La mediación cognitiva: los me-dios presentan aconteceres novedosos y los confrontan con las normas sociales interpretadas, es decir, presentan relatos basados en modelos de representación del mundo, y

b) La mediación estructural: los medios adaptan las informaciones a las posibilidades de sus formas expresivas e intentan perpetuar dicha forma. Es decir, se organizan a partir de modelos de comunicación.

Entendemos por "medios de comunicaciones sociales" aquellos instrumentos técnico-artísticas de transmisión audiovisual, que presentan estas tres características: 1) En un mismo momento, 2) Emiten idéntico mensaje, 3) A un número elevado de personas. Estas tres características deben darse a la vez e inseparablemente. (AA.VV., 1990, p. 64). En ciertos momentos culturales se han denominado «medios de comunicación de masas», «mass-media» -terminología anglosajona-, o simplemente, «medios de masas». Los podemos considerar sinónimos.

Debido a los avances tecnológicos de los medios, éstos van siendo cada vez más atractivos y manipuladores de las personas. También hay que añadir que los MCS contribuyen, sin lugar a dudas, a la homogeneización de la cultura, del pensamiento, del gusto, del deseo, creando cánones o patrones de fuerte influencia.

De todas formas, según estudios realizados sobre los MCS, el receptor selecciona los mensajes de acuerdo con su personalidad, su ambiente social, su autoimagen, la imagen que tiene del medio (Maletze, 1965; Benito, 1982). Por lo tanto, se deja cierto margen de libertad al receptor.

De acuerdo con Roland Barthes (1972 p. ) "Para descifrar el significado de realidades complejas o dudosas no basta con simplemente mirarlas, es necesario poner una mayor atención para ob- 
servar todos los elementos que la componen. La percepción se dirige primeramente a aquellos estímulos que más llaman la atención (campo focal), para posteriormente "recorrer" los otros factores que entran en juego y que rodean a los primeros estímulos, y de este modo obtener una visión completa que permita reconocer su intencionalidad."

\section{Metodología}

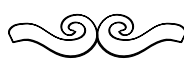

\section{a) Enfoque}

Hemos utilizado el método cuantitativo en el uso de encuestas aplicadas a niños de segundo grado de la Escuela Primaria de Pachuca "Profesor Teodomiro Manzano", para mesurar el grado de influencia que tienen las películas infantiles en los niños. Con ayuda del método cualitativo se verifica que los niños tengan una evolución en el proceso de la encuesta.

\section{b) Alcance}

La investigación obtuvo un alcance exploratorio ya que capta los componentes y características fundamentales de la relación niño-valores.

\section{c) Diseño}

La estrategia no experimental en los grupos de segundo año de la primaria Profesor Teodomiro Manzano el día 19 de Mayo del año 2008, demuestra un tipo transaccional ya que en un estilo exploratorio nos hizo recolectar información sobre los valores involucrados en las películas de Disney.

\section{d) Contexto}

La investigación se realizó tomando en cuenta a los niños de entre 7 y 8 años, para lo cual tomamos como muestra a los alumnos de segundo año de la escuela primaria Profesor Teodomiro Manzano.

Se aplicó una encuesta conformada de doce preguntas referentes a las películas y a los valores que reciben de éstas. Se realizó el día 19 de mayo de 2008, entre las 10:30 AM y las 12:30 PM, a los dos grupos de segundo grado, siendo un total de 26 niños y 25 niñas quienes contestaron la encuesta.

\section{f) Sujeto}

Los sujetos de la investigación son los niños que encuentran en el cine un factor de entretenimiento y educación con valores.

\section{g) Población}

Los niños de entre 7 a 12 años que consumen películas infantiles.

\section{h) Muestra}

Alumnos de segundo y sexto grado del Colegio Profesor Teodomiro Manzano del turno matutino de la ciudad Pachuca de Soto, Hidalgo.

\section{i) Supuesto}

Se espera explorar como los medios de comunicación masiva, en este caso el cine infantil, cumple las funciones de entretener y educar, sin deteriorar la conducta o el comportamiento de la audiencia, como lo pueden ser los niños, Así mismo el aprendizaje vicario influye de manera significativa en los seres humanos y más aún en los niños, ya que son demasiado perceptivos.

\section{j) Procedimiento}

Comenzamos con la identificación del tema que queríamos abordar ya que el cine infantil como medio de comunicación es un factor importante en el desarrollo de valores en los niños, específicamente en niños de 8 y 9 años. Después proseguimos al reconocimiento de posibles investigaciones que se acercaran a la que nosotros proponíamos, así mismo nos adentramos a la terminología adecuada para poder entender y desarrollar mejor el tema. Posteriormente decidimos aplicar una encuesta en la escuela primaria Profesor Teodomiro Manzano ya que en esta escuela obtuvimos la autorización para trabajar con dos grupos de segundo grado. Asistimos el día 19 de mayo entre las $10: 30$ y las 12 del día, nos atendió la directora de la institución la cual nos dirigió al primer grupo de segundo grado; después de realizar la encuesta en este salón nos dirigimos al segundo grupo, los cuales arrojaron datos interesantes que presentaremos más adelante. 
k) Técnica

A continuación se presenta la encuesta aplicada:

Edad

Sexo

1.- ¿Ves películas?

$\mathrm{Si}$ No

2. - Marca con una "X” ¿Cuántas películas ves en casa a la semana?
( ) Una
( ) Dos
( ) Más de tres

3. -Marca con una " $X " ~ ¿ C$ Cuantas veces vas al cine al mes:

( ) Unós de tres ( ) Dos

4.- Subraya ¿Cuándo ves películas, alguien te acompaña?

( )Familiar ( )Amigo ( )Ambos

( ) No, estoy solo

( )Otro

5.- De los siguientes valores escoge cuatro que estén en las películas que ves:
( ) Bondad
( ) Esperanza
( ) Templanza
( ) Valentía
( ) Respeto
( ) Honestidad
( ) Amistad
( ) Libertad
( ) Solidaridad

6.- Después de ver la película, ¿Platicas con alguien de qué trató?

¿Quién?

Sí No A veces

7.- Marca con una " $x$ " de las siguientes películas, la que ya viste:

( ) El Rey León ( ) La Espada en la piedra.

( ) La Sirenita

8.- Subraya cuál de estos tres personajes te gusta más.

Ariel Simba Grillo
9.- ¿Te gustan los finales de las tres películas que mencionamos anteriormente o preferirías cambiarlos?
( ) Me gustan como están
( ) Cambiaria alguno ¿Por qué?

10.- ¿Prefieres al bueno o al villano de las películas mencionadas?
( ) Bueno
( ) Villano
¿Por qué?

11.- ¿Por qué crees que siempre gana el bueno en estas películas?

12.- ¿Quién representa más valores para ti?

$\begin{array}{ll}\text { () Un Superhéroe } & (\text { ) Una caricatura } \\ \text { ( ) Un familiar } & (\text { ) Otros }\end{array}$

GRACIAS POR PARTICIPAR

\section{Resultados}

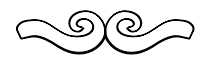

La encuesta fue aplicada el 19 de mayo DE 2008 entre las 10:30 AM y las 12:00 PM en la escuela profesor Teodomiro Manzano

Se realizó a los dos grupos de segundo grado de primaria, tomando un número de 26 niños y 25 niñas, donde:

El $100 \%$ de la población tanto de niños como de niñas de segundo grado contestaron que si ven películas, de las cuales más de un $60 \%$ de los niños y un $84 \%$ de las niñas ven 2 o más películas en su casa a la semana, mientras que un $60 \%$ de niños y niñas acuden dos o más veces por mes a ver películas al cine.

Al ver películas un $65 \%$ de los niños y un $68 \%$ de las niñas son acompañados por alguien de su familia, predominantemente con sus padres. 
Los valores que recuerdan de las películas son:

\begin{tabular}{|l|l|l|}
\hline & Niños \% & Niñas \% \\
\hline Bondad & 46 & 72 \\
\hline Templanza & 38 & 72 \\
\hline Respeto & 61 & 96 \\
\hline Amistad & 92 & 92 \\
\hline Libertad & 57 & 68 \\
\hline Solidaridad & 26 & 64 \\
\hline Esperanza & 42 & 64 \\
\hline Valentía & 84 & 80 \\
\hline Honestidad & 34 & 76 \\
\hline
\end{tabular}

Esto se debe a que después de ver una película un $65 \%$ de los niños y un $76 \%$ de las niñas, platican con sus padres acerca de la película.

Dentro de las películas que se mencionaron en la encuesta, El Rey León ya ha sido vista por un $96 \%$ de los niños y un $84 \%$ por las niñas; La Espada en la Piedra ha sido vista por un $65 \%$ de los niños y un $44 \%$ de las niñas; La Sirenita en un $61 \%$ por los niños y en un $100 \%$ por las niñas. Siendo Simba el personaje preferido de los niños en un $70 \%$ y Ariel el de las niñas en un $96 \%$.

Al preguntarles qué personaje preferían en las películas, si al bueno o al villano; el $73 \%$ de los niños y el $84 \%$ de las niñas prefirieron al personaje bueno, y al preguntarles por qué creían que este siempre ganaba, alrededor del $70 \%$ tanto de niños como de niñas se lo atribuía a alguna cualidad que hacía referencia a los valores, ya sea por el simple hecho de ser bueno o por que protegía a sus amigos.

Los niños identifican más valores en distintas personas o caricaturas de la siguiente forma:

\begin{tabular}{|l|l|l|}
\hline & Niños \% & Niñas \% \\
\hline Superhéroe & 57 & 20 \\
\hline Caricatura & 23 & 12 \\
\hline Familiar & 15 & 56 \\
\hline Otro & 3 & 12 \\
\hline
\end{tabular}

\section{Conclusiones}

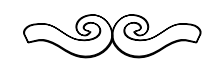

\section{a)Discusión}

En esta investigación se contraponen dos puntos de vista muy comunes actualmente, Se asume que el cine en la actualidad es un medio de comunicación en el cual existe exceso de violencia. En nuestra investigación, por lo contrario se considera que el cine es un medio que permite también enseñar valores y actitudes positivas en los niños.

\section{b) Aportación}

Ésta investigación ayuda a comprender lo importante del aprendizaje vicario en los niños, así mismo cómo el cine, siendo un medio de comunicación, puede acrecentar sus valores, ya que un $60 \%$ de los niños encuestados así como un $84 \%$ de las niñas ven 2 o más películas en su casa. Así mismo descubrimos que más de la mitad de niños y niñas son acompañados por algún familiar a ver las películas. Lo anterior permite observar que puede existir un acompañamiento que en algunas ocasiones permita una explicación hacia el niño de las escenas que acaba de observar, así, existe una mejor interpretación del niño de lo que acaba de ver.

Gracias a las encuestas realizadas y visitas a la escuela Profesor Teodomiro Manzano, tuvimos la oportunidad de entrevistar a tres alumnos de sexto grado de primaria, donde encontramos un cambio de actitud muy drástico ya que se sentían identificados, pero de diferente manera con los personajes. Comenzaron a negar con- 
sumir, o haber visto esos productos ya que los consideraban infantiles. Así mismo nos pudimos percatar de que el nivel de valores que manejan es distinto, debido a la etapa en que viven dónde buscan encontrar y reafirmar su identidad.

\section{c) Límites}

Los hechos que nos pusieron barreras que se presentaron fue en un salón de segundo grado debido a que la profesora se ausentó un momento y eso provocó que los encuestados desviaran su atención, así como la falta de actitud positiva de los niños de sexto grado para la realización de la encuesta.

\section{d) Objetivos Cumplidos}

Gracias a la técnica aplicada podemos concluir que en las películas seleccionadas, los niños identifican valores como la amistad y sinceridad, la posibilidad de encontrar bondad y maldad en los personajes, así como mostrar una situación de relaciones familiares.

\section{e) Preguntas Resueltas}

Las películas infantiles se consideran como un producto consumible de los niños donde aproximadamente un $60 \%$ es acompañado, o donde se explica el contenido para ser entendido. Los valores que identifican los niños en las películas infantiles son bondad, templanza, respeto, amistad, libertad, solidaridad, esperanza, valentía y honestidad. La preferencia del personaje se ve identificada dependiendo del género del niño.

En las películas propuestas se cumple la función de entretener y educar porque los encuestados demuestran con los resultados la capacidad de encontrar valores y diversión en los filmes, es decir, aspectos educativos y entretenimiento.

Gracias a distintas películas que han visto, así como su entorno social, los niños logran diferencia entre bondad y maldad. La influencia de este medio para generar valores en los niños se encuentra como un factor de reforzamiento para su formación.

\section{f) ¿Cumplió el supuesto?}

Se exploró que los medios de comunicación masiva, como el cine infantil pueden cumplir las funciones de entretener y educar, sin deterio- rar la conducta y el comportamiento de los niños, Así mismo el aprendizaje vicario influye en ellos gracias a su fácil capacidad de percepción y retención.

\section{g) Beneficios de la investigación}

Con esta investigación logramos observar que los niños al principio de su infancia desarrollan valores y actitudes positivas que a lo largo del tiempo se van modificando.

Los niños tienen la necesidad de encontrar un guía en las películas para mostrarlo en su vida cotidiana.

Los valores que encuentran en las películas los relacionan con su familia, amigos y escuela.

El cine infantil es un factor que ayuda a la formación educativa y social en la infancia.

\section{h) Habilidades que se desarrollaron con esta investigación}

Logramos ampliar nuestra paciencia e interacción con los niños. Tratamos de mantener una imagen positiva de la Universidad La Salle Pachuca. También adquirimos mayor conocimiento.

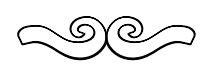




\section{Fuentes de consulta}

ARANGUREN, José Luís (1979) Ética Ed. Madrid. Pp. 140-147.

BARTHES, Roland, (1972) La retórica de la imagen, en Comunicaciones Núm. 4 Tiempo contemporáneo. Buenos Aires.

El mundo del Cine. Los grandes mitos del séptimo arte. (2000) Ed. Oceano, Barcelona Pp. 15, 67,145-146, 154.

FINGERMANN, Gregorio (1970) Relaciones Humanas Fundamentos psicológicos y sociales. Buenos Aires. En Colección de Estudios Humanísticos. Ed. El Ateneo. Pp. 120-123.

KOHLBERG, Lawrence (1985) Desarrollo Moral en Gran Enciclopedia Didáctica Ilustrada Salvat. (Tomo 9, Pp. 22) España: Salvat Editores.

LABINOWICZ, E. (1986) Introducción a Piaget. Pensamiento. Aprendizaje. Enseñanza. México, Ed. Fondo Educativo Interamericano. S. A. Sistemas Técnicos de Edición. S. A. Pp. 30-57 NEWMAN, Phillip (2004) Desarrollo del niño. México. Ed. Limusa. Pp. 22-23.

PLIEGO, María (2002) Valores y autoeducación. (11a. edición) México Ed. Minos MARTíNEZ, Enrique (2008) Página web de Universidad de Huelva, España: http://www.uhu. es/cine.educacion/cineyeducacion/index.htm Industria cinematográfica y audiovisual. (2008) Ministerio de Cultura, pagina web de gobierno de España: http://www.mcu.es/cine/CE/Industria/DefinicionPelicula.html

Lista alfabética de autores (2008), pagina web de Portal Infoamérica http: / /www.infoamerica. org/teoria/bandura1.htm

TEJEDA, María. [I.] (2007). El Cine Infantil como Instrumento Didáctico, El portal educativo del Estado Argentino. Recuperado Mayo de 2008 de Educar, el portal del Estado Argentino.

http://portal.educ.ar/debates/eid/lengua/ publicaciones/el-cine-infantil-como-instrumento-didactico.php

BUXARRIAIS, María. [I.] (1996) Los medios de comunicación y la educación en valores. Publicado previamente en Revista Pensamiento Educativo de la Universidad Católica de Chile, Recuperado Mayo de 2008. Obtenido de la página web: http://www.robertexto.com/archivo15/medios_educacion.htm 